\title{
Ag-induced a New Raman Mode in ZnO Microrods
}

\section{Lina WANG ${ }^{1,2}$, Jing WANG ${ }^{2}$, , Meina WANG ${ }^{3}$, Dan ZHOU ${ }^{2}$, Yan MEI ${ }^{2}$, Wenzhuo HUANG ${ }^{2}$, Tian XING ${ }^{2}$, Shengxu GE ${ }^{2}$,Yuntong CHEN ${ }^{2}$, You YU ${ }^{2}$, Zhongqi LUAN ${ }^{2}$, Bing QU ${ }^{2}$, Yaxiang BAI ${ }^{2}$, Chao PAN ${ }^{2}$, Delong TANG ${ }^{2}$, Na $\mathrm{ZHU}^{2}$, Yu QIU ${ }^{1}$, Lizhong HU ${ }^{1}$}

\author{
${ }^{1}$ School of Physics and Optoelectronic Technology, Dalian University of Technology, Dalian 116024, China \\ ${ }^{2}$ Key Laboratory of Marine Biophysics of Liaoning Province, Dalian Ocean University, Dalian 116023, China \\ ${ }^{3}$ Educational Technology Center, Shenyang Medical College, Shenyang110034, China \\ cross $^{\text {ref }}$ http://dx.doi.org/10.5755/j01.ms.25.3.19130
}

Received 27 September 2017; accepted 13 April 2018

\begin{abstract}
The chemical vapor deposition technique was used to prepare the Ag doped $\mathrm{ZnO}$ microrods, which were located on $\mathrm{Si}$ substrates at two different positions. The scanning electron microscopy revealed that the samples have a clear hexagonal shape. X-ray diffraction provided information about the preferential orientation along the c-axis. The Raman analysis revealed that a new Raman mode appears at $492 \mathrm{~cm}^{-1}$ due to Ag doping. As this mode has not been reported early, it could be used as a characteristic mode of Ag doping in Raman spectrum. The red shift of the $\mathrm{E}_{2}$ (high) mode proves the existence of tensile stress in the samples.
\end{abstract}

Keywords: $\mathrm{ZnO}$ microrods, Ag doping, Raman spectrum.

\section{INTRODUCTION}

Because of the wide band gap and relatively large exciton binding energy, $\mathrm{ZnO}$ has stimulated a range of research interests for short wavelength optoelectronic devices [1], surface acoustic waveguides [2], solar cells [3], gas sensors [4], and some piezoelectric devices [5]. There has been a lot of efforts to find out the physical, optical, and electrical properties of nano structures, even in the applications in constructing micro-nano scale electronic or optoelectronic devices. To date, many $\mathrm{ZnO}$ nanostructures have been constructed, such as nanorods, nanotubes, nanoplates, nanonails, and nanowires. Many dopants, such as $\mathrm{Ag}$ and $\mathrm{Cu}$, have been used to adjust the properties of $\mathrm{ZnO}$ nanostructures [6,7]. As an element of group-IB, Ag can act as acceptor in $\mathrm{ZnO}$, which can occupy the substitutional $\mathrm{Zn}$ or the interstitial sites [8].

The properties of the doped $\mathrm{ZnO}$ micro-nanostructures are strongly dependent upon the deposition method, doping elements, substrate, and intrinsic defects [9]. Many synthesis techniques are applied to prepare doped $\mathrm{ZnO}$, such as the electrochemical solution method [10], modified thermal-evaporation process [11], aqueous-based chemical method [12], and chemical vapor deposition [13]. The chemical vapor deposition (CVD) method is a much simpler technique under stable and reproducible conditions when compared to the other techniques [14]. Furthermore, the Raman scattering technique is a non-destructive and valuable test to study the phonon behavior of doped $\mathrm{ZnO}$ materials. It can also provide the lattice dynamics, defects, and information of the crystal structure.

In this paper, the $\mathrm{Ag}$ doped $\mathrm{ZnO}$ microrods (AZMR) were synthesized by Chemical Vapor Deposition (CVD) method on Si substrates. The influence of Ag elements on morphologies and Raman properties were thoroughly studied. Raman spectra reveals that due to Ag doping there is a vibrational mode at $492 \mathrm{~cm}^{-1}$, which has not been reported by other researchers.

\section{EXPERIMENTAL DETAILS}

The horizontal tube furnace equipment was used to deposit the AZMR on Si substrate by the CVD method. The CVD system was composed of three parts: a gas controller, a temperature control system, and a horizontal tube furnace. Fig. 1 shows the illustration of the experimental system. A mixture powder of $\mathrm{ZnO}(2 \mathrm{~g})$, graphite $(0.4 \mathrm{~g})$, and $\mathrm{Ag}_{2} \mathrm{O}(2 \mathrm{~g})$, which each act as a reaction source, were placed at one end of a quartz tube (diameter $3 \mathrm{~cm}$, length $35 \mathrm{~cm}$ ). The two $\mathrm{Si}$ substrates were placed downstream of the mixture powders, with sample a being placed $10 \mathrm{~cm}$ away from the mixture powders and sample $\mathrm{b}$ being placed $30 \mathrm{~cm}$ away.

While amidst a mixture gas of $\mathrm{N}_{2}$ and $\mathrm{O}_{2}(100 \mathrm{sccm}$ for $\mathrm{N}_{2}$ and $40 \mathrm{sccm}$ for $\mathrm{O}_{2}$ ), the growth temperature of the mixture powders was maintained at a temperature of $950{ }^{\circ} \mathrm{C}$ for 60 minutes. The furnace system was chill-down to room temperature with constant flow of $\mathrm{N}_{2}$ after growth. Subsequently, AZMR was found on the surface of sample $\mathrm{a}$, and $\mathrm{Ag}$ doped $\mathrm{ZnO}$ micromultiple (AZMM) was found on the surface of sample $b$.

The morphology of the sample was studies in a Hitachi SU1510 scanning electron microscope (SEM) operating at $20 \mathrm{kV}$. The energy dispersive X-ray spectroscopy (EDS) attached to the SEM was used to analyze elemental composition. The structural properties were analysed by Xray diffraction (XRD; RigakuD/max3B), which was performed in a $\theta-2 \theta$ configuration. The micro-Raman system (Jobin Yvon LabRAM HR 800UV) was used to characterize the optical properties at room temperature.

\footnotetext{
* Corresponding author. Tel.: +86-0411-84763979;

fax: +86-0411-84709304. E-mail address:1.n.w@163.com (J. Wang)
} 


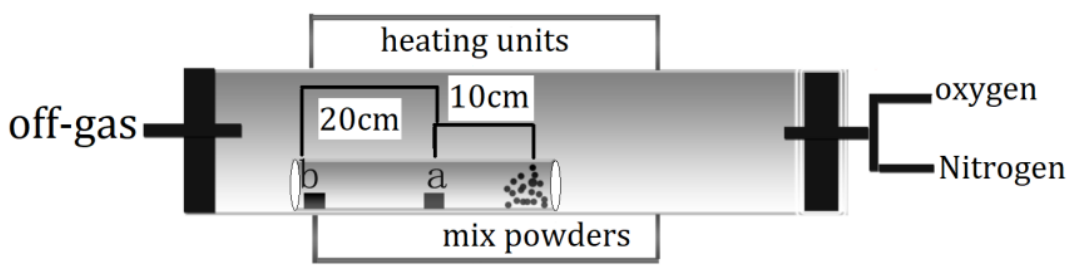

Fig. 1. The illustration of experimental system.

\section{RESULTS AND DISCUSSION}
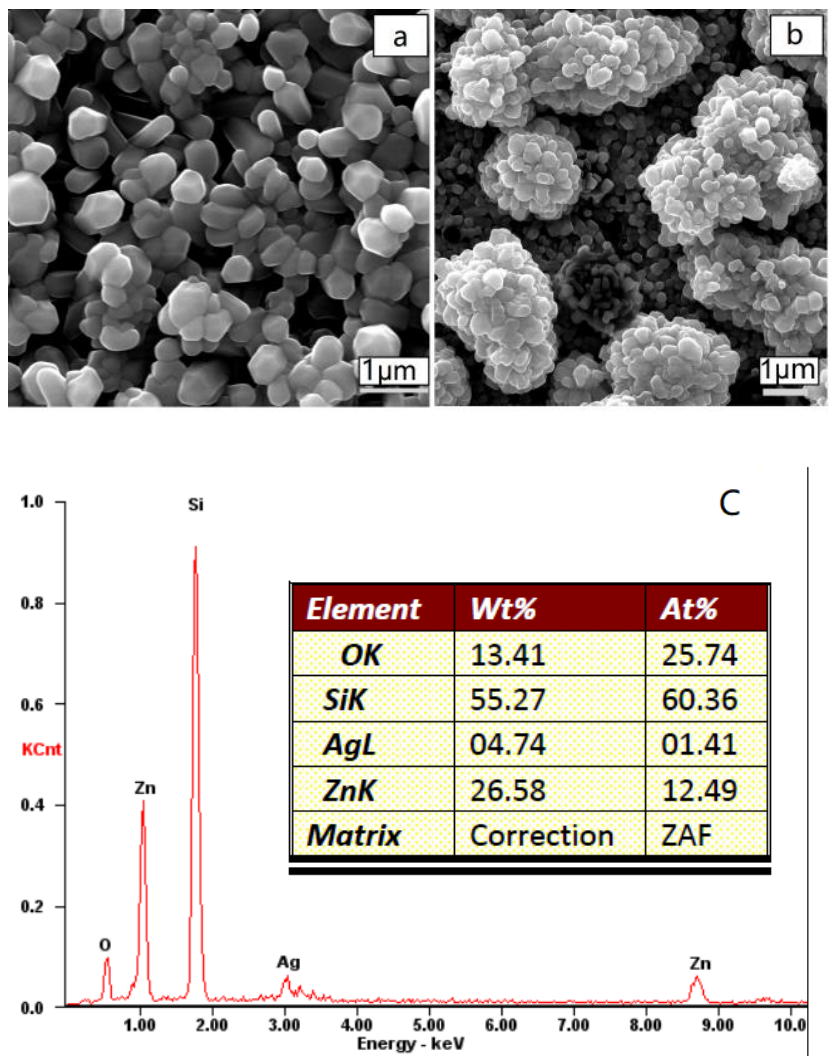

Fig. 2. SEM images of $\mathrm{Ag}$ doped $\mathrm{ZnO}$ microrods: $\mathrm{a}-10 \mathrm{~cm}$ away from the vapour source; $\mathrm{b}-30 \mathrm{~cm}$ away; $\mathrm{c}-\mathrm{EDX}$ spectra of sample b

The SEM images of AZMR and AZMM shown in Fig. 2 give a general view of microstructures on the $\mathrm{Si}$ substrates. As shown in Fig. 2 a, uniform Ag doped $\mathrm{ZnO}$ microrods can be observed with about $400 \mathrm{~nm}$ in diameter and up to $700 \mathrm{~nm}$ in length. The microrods each move in the vertical direction and are all almost uniform in length and size. Furthermore, the figure shows that the microrods have a clear hexagonal shape with smooth and clean side walls. This hexagonal morphology means that the $\mathrm{ZnO}$ microrods have a perfect wurtzite structures. Fig. 2 indicates that the AZMR have a preferential c-axis growth direction, and it was in $\{100\}$ the hexagonal facet. Fig. 2 b shows the SEM images of sample $b$, which display the $\mathrm{ZnO}$ micromultiple structures. Just as sample a, the base layer is $\mathrm{Ag}$ doped $\mathrm{ZnO}$ microrods and the top layer is $\mathrm{Ag}$ doped lumps-like $\mathrm{ZnO}$ micro-nanostructure. Fig. $2 \mathrm{c}$ shows the EDX spectra of sample b, the Ag peak appears at $3.0 \mathrm{keV}$, which means the $\mathrm{Ag}$ successfully doped in the nanostructures. The mass ratio of $\mathrm{Ag}$ and $\mathrm{Zn}$ is about 1:5.6. because of the different melting point, only part of the Ag doped in the nanostructure during the whole process.

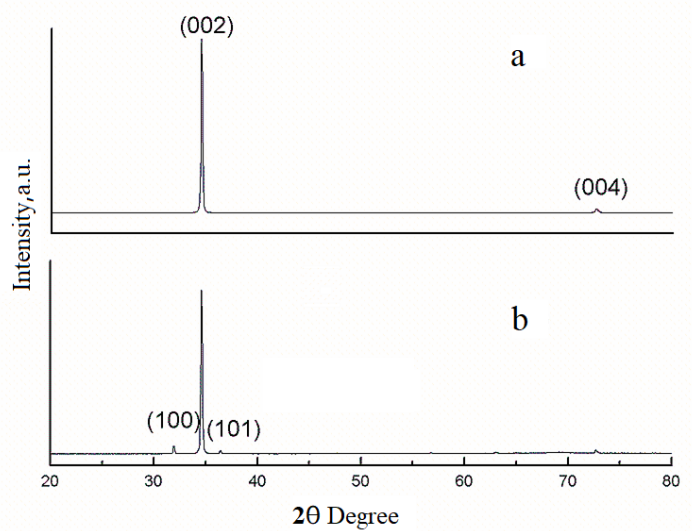

Fig. 3. XRD patterns of sample $a$ and $b$

The reason for the difference between the two samples can be attributed to the substrate temperature. Sample a is next to the evaporation source, therefore it is in the heating zone and the substrate temperature is high. Sample b is out of the heating zone, leading to a lower substrate temperature than sample a and different morphology between the two samples.

The relationship between temperature and $\mathrm{ZnO}$ nanostructures was studied by Wang et al., who believed that two reasons may be responsible for the difference: the changing of $\mathrm{ZnO}$ vapor and the different thermal expansion coefficient between the substrate and nanostructures [15].

Fig. 3 shows the XRD patterns of sample a and sampleb. Four peaks can be observed: with the Miller indices (hkl), namely (100), (002), (101), (004). For the standard hexagonal $\mathrm{ZnO}$, the 2-theta value of the four peaks were separately located at $31.77^{\circ}, 34.45^{\circ}, 36.25^{\circ}$, and $72.56^{\circ}$. Corresponding to $\mathrm{ZnO}$ (002) peak, the figure shows that the peaks at about $34.31^{\circ}$ and $34.37^{\circ}$ are very strong, and aside from $\mathrm{ZnO}$, no phases related to $\mathrm{Ag}$ oxides can be observed. This indicates that $\mathrm{Ag}$ doped $\mathrm{ZnO}$ micronanostructures have a hexagonal wurtzite structure and a preferential orientation along the c-axis. Compared to pure $\mathrm{ZnO}$, the (002) peak located at $34.45^{\circ}$ has a slight shift to the lower $2 \theta$ angle direction. This is primarily because the ionic radius of $\mathrm{Ag}^{+}(122 \mathrm{pm})$ is larger than $\mathrm{Zn}^{2+}(72 \mathrm{pm})$. As a dopant in $\mathrm{ZnO}, \mathrm{Ag}$ can occupy the interstitial $\left(\mathrm{Ag}_{\mathrm{i}}{ }^{*}\right)$ or substitutional $\mathrm{Zn}^{2+}$ sites $\mathrm{Ag}^{\prime} \mathrm{Zn}$ [8].

The Raman scattering technique is non-destructive and a stable test to study the defects, structural disorder, and 
crystalline quality in the doped $\mathrm{ZnO}$ micro-nanostructures. It can provide important information about the change of local structure, owing to the incorporation of doped ions. According to the group theory, $\mathrm{ZnO}$ single crystal is in the $\mathrm{C}_{6 \mathrm{v}}$ point group symmetry, including two Raman silence $\mathrm{B}_{1}$ modes and six other Raman phonon modes [16]. The two $\mathrm{E}_{2}$ modes are divided into high and low frequencies located at 437 and $101 \mathrm{~cm}^{-1}$. The $A_{1}$ and $E_{1}$ modes are separated into transverse and longitudinal modes. The two $\mathrm{A}_{1}$ modes are 380 and $574 \mathrm{~cm}^{-1}$, and the two $\mathrm{E}_{1}$ modes are 407 and $583 \mathrm{~cm}^{-1}$.

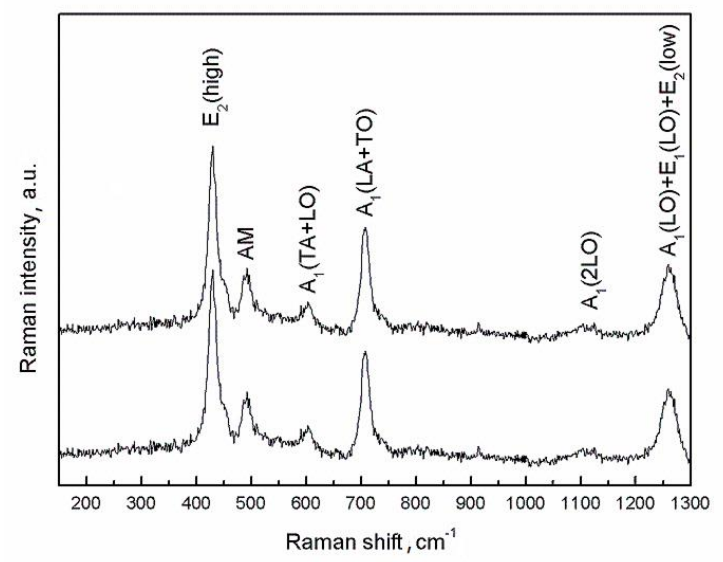

Fig. 4. The Raman spectra of sample $a$ and $b$

Fig. 4 shows the Raman scattering of sample a and sample b over the $100-1300 \mathrm{~cm}^{-1}$ range. There are not many other differences between the two samples. The peak at $429 \mathrm{~cm}^{-1}$ is $\mathrm{E}_{2}$ (high) mode, this mode has a strong relationship with the wurtzite structure of $\mathrm{ZnO}$; it's intensity indicates the perfect crystallinity. The shift of the $\mathrm{E}_{2}$ mode provides information about stress: the compressive stress was dominating if shifting in the direction of high frequency, and the tensile stress was dominating when shifting in the other direction [17]. When compared with the stand mode, the $E_{2}$ (high) mode of standard $\mathrm{ZnO}$ was located at $437 \mathrm{~cm}^{-1}$. An $8 \mathrm{~cm}^{-1}$ downshift was observed, which means the two samples both have tensile stress. The second order of Raman peaks with $A_{1}$ symmetry $\left(601,706,1108 \mathrm{~cm}^{-1}\right)$ can also be observed. The $A_{1}(\mathrm{LO})+\mathrm{E}_{1}(\mathrm{LO})+\mathrm{E}_{2}$ (low) peak was located at $1262 \mathrm{~cm}^{-1}$ as a result of the multiple phonon scattering processes. Apart from the peaks mentioned above, the local vibration mode (LVM) at $492 \mathrm{~cm}^{-1}$ with strong intense could also be found. The LVMs caused by other dopants were also found, such as $\mathrm{Fe}, \mathrm{Ga}$, and $\mathrm{Sb}$ doped ZnO films; the LVMs were located at 720, 631, and $531 \mathrm{~cm}^{-1}$, respectively [18]. They believed the LVMs were caused by doped elements and can be used as incorporation indicators. After depositing $\mathrm{Ag}$ doped $\mathrm{ZnO}$ films on sapphire substrate by pulsed laser deposition, we found a LVM at $492 \mathrm{~cm}^{-1}$, which was induced by Ag doping [19]. Therefore, we presume that the Raman mode at $492 \mathrm{~cm}^{-1}$ should be attributed to LVM caused by Ag doping. AZMR, AZMM, and Ag doped $\mathrm{ZnO}$ films were each synthesized using different methods on different substrates; both LVMs at $492 \mathrm{~cm}^{-1}$ appeared. Thus, this mode should be marked as a symbol of $\mathrm{Ag}$ incorporation into the $\mathrm{ZnO}$ micronanostructures.

\section{CONCLUSIONS}

In summary, the CVD method was used to synthesize $\mathrm{Ag}$ doped $\mathrm{ZnO}$ microrods on $\mathrm{Si}$ substrates. The SEM results show that the samples have a hexagonal structure and are grown in the preferential c-axis direction. The XRD patterns also corroborate the hexagonal wurtzite structure and proves that the samples were growing along the c-axis. Raman spectrum portrays the existence of stress in the samples and a characterized Raman mode at $492 \mathrm{~cm}^{-}$ ${ }^{1}$ could be indicative of the successful $\mathrm{Ag}$ doping in $\mathrm{ZnO}$ microstructures. The mechanism that doping with Ag can induce an extra Raman mode may in connection with the location of $\mathrm{Ag}^{+}$, further studied can be made to discuss whether it can be represent $\mathrm{Ag}_{\mathrm{i}}$ * or $\mathrm{Ag}^{\prime} \mathrm{Zn}$.

\section{Acknowledgments}

This work was supported by the Nature Science Foundation of Liaoning Province (No. 20170540109 and No.201601285).

\section{REFERENCES}

1. Qiu, Y., Zhang, H.Q., Hu, L.Z., Wang, L.N., Wang, B., Yang, D.C., Liu, G.Q., Ji, J.Y., Liu, X., Lin, J.F., Lang, Y., Li, F., Han, S.J. Improving the Quality of Schottky Contacts on $\mathrm{ZnO}$ Microwires Using $\mathrm{Cu}$-Contained Silver Paste Electrode Micro \& Nano Letters 7 (6) 2012: pp. $592-595$.

https://doi.org/10.1049/mnl.2012.0269

2. Verardi, P., Nastase, N., Gherasim, C., Ghicac, C., Dinescud, M., Dinud, R., Fluerarub, C. Scanning Force Microscopy and Electron Microscopy Studies of Pulsed Laser Deposited ZnO Thin Films. Application to the Bulk:Acoustic Waves(BAW) Devices Journal of Crystal Growth 197 (3) 1999: pp. 523-528. https://doi.org/10.1016/S0022-0248(98)00808-2

3. Rau, U., Schmidt, M. Electronic Properties of $\mathrm{ZnO} / \mathrm{CdS} / \mathrm{Cu}$ (In, Ga) Se-2 Solar Cells Aspects of Heterojunction Formation Thin Solid Films 387 (1) 2001: pp. 141-146. https://doi.org/10.1016/S0040-6090(00)01737-5

4. Yamazaki, T., Wada, S., Noma, T., Suzuki, T. Gassensing Properties of Ultrathin Zinc-Oxide Films Sensors and Actuators B 14 (93) 1993: pp. 594-595. https://doi.org/10.1016/0925-4005(93)85106-K

5. Zhou, J., Gu, Y., Fei, P., Mai, W., Gao, Y. Flexible Piezotronic Strain Sensor Nano Letters 8 (9) 2008: pp. 3035-3040. https://doi.org/10.1021/n1802367t

6. Ren, C.L., Yang, B.F., Wu, M., Xu, J., Fu, Z., Lv, Y., Guo, T., Zhao, Y., Zhu, C. Synthesis of Ag/ZnO Nanorods Array with Enhanced Photocatalytic Performance Journal of Hazardous Materials $182(1-3)$ 2010: pp. 123-129. https://doi.org/10.1016/j.jhazmat.2010.05.141

7. Zeferino, R.S., Flores, M.B., Pal, U. Photoluminescence and Raman Scattering in Ag-doped ZnO Nanoparticles Journal of Applied Physics 109 (1) 2011: pp. 065303. https://doi.org/10.1063/1.3530631

8. Bian, H.Q., Ma, S.Y., Zhang, Z.M., Gao, J.M., Zhu, H.B. Microstructure and Raman Scattering of Ag-doping $\mathrm{ZnO}$ Films Deposited on Buffer Layers Journal of Crystal Growth 394 (394) 2014: pp. $132-136$. https://doi.org/10.1016/j.jcrysgro.2014.02.036 
9. Hu, Z.G., Li, W.W., Wu, J.D., Sun, J., Shu, Q.W. Optical Properties of Pulsed Laser Deposited Rutile Titanium Dioxide Films on Quartz Substrates Determined by Raman Scattering and Transmittance Spectra Apply Physics Letters 93 (18) 2008: pp. 7454 https://doi.org/10.1063/1.3021074

10. Liang, J.K., Su, H.L., Kuo, C.L., Kao, S.P., Cui, J.W. Structural, Optical and Electrical Properties of Electrodeposited Sb-Doped $\mathrm{ZnO}$ Nanorod Arrays Electrochimica Acta 125 (12) 2014: pp. 124-132. https://doi.org/10.1016/j.electacta.2014.01.029

11. Fan, D.H., Zhang, R., Li, Y. Synthesis and Optical Properties of Phosphorus-Doped ZnO Nanocombs Solid State Communications 150 (39) 2010: pp. 1911-1914. https://doi.org/10.1016/j.ssc.2010.07.036

12. Panigrahy, B., Aslam, M., Bahadur, D. Aqueous Synthesis of $\mathrm{Mn}$ - and Co-Doped $\mathrm{ZnO}$ Nanorods The Journal of Physical Chemistry C 114 (27) 2010: pp. 11758-11763. https://doi.org/10.1021/jp102163b

13. Ding, M., Yao, B., Zhao, D., Fang, F., Shen, D. The Effect of Arsenic Thermal Diffusion on the Morphology and Photoluminescence Properties of Sub-Micron $\mathrm{ZnO}$ Rods Thin Solid Films 518 (15) 2010: pp. 4390-4393. https://doi.org/10.1016/j.tsf.2010.02.009

14. Suh, D.I., Byeon, C.C., Lee, C.L. Synthesis and Optical Characterization of Vertically Grown $\mathrm{ZnO}$ Nanowires in High Crystallinity Through Vapor-Liquid-Solid Growth Mechanism Applied Surface Science 257 (5) 2010: pp. $1454-1456$. https://doi.org/10.1016/j.apsusc.2010.08.067

15. Wang, X.H., Li, R.B., Fan, D.H. Control Growth of Catalyst-Free High-Quality $\mathrm{ZnO}$ Nanowire Arrays on Transparent Quartz Glass Substrate by Chemical Vapor Deposition Applied Surface Science $257(7)$ 2011: pp. 2960-2964. https://doi.org/10.1016/j.apsusc.2010.10.100

16. Youn, C.J., Jeong, T.S., Han, M.S., Kim, J.M. Optical Properties of Zn-Terminated ZnO Bulk Journal of Crystal Growth 261 (4): 2004: pp. 526-532. https://doi.org/10.1016/j.jcrysgro.2003.09.044

17. Huang, Y., Liu, M., Li, Z., Zeng, Y., Liu, S. Raman Spectroscopy Study of ZnO-Based Ceramic Films Fabricated by Novel Sol-Gel Process Materials Science and Engineering $B \quad 97$ (2) 2003: pp. 111-116. https://doi.org/10.1016/S0921-5107(02)00396-3

18. Bundesmann, C., Ashkenov, N., Schubert, M., Spemann, D., Butz, T. Raman Scattering in ZnO Thin Films Doped With $\mathrm{Fe}, \mathrm{Sb}, \mathrm{Al}, \mathrm{Ga}$ and Li Apply Physics Letters 83 (10) 2003: pp. 1974-1976. https://doi.org/10.1063/1.1609251

19. Wang, L.N., Hu, L.Z., Zhang, H.Q., Qiu, Y., Lang, Y. Studying The Raman Spectra of Ag Doped ZnO Films Grown by PLD Materials Science in Semiconductor Processing $14(3-4)$ 2012: pp. 274-277. https://doi.org/10.1016/j.mssp.2011.05.004 